\title{
REFLECTIONS
}

\section{Getting the News}

Roger A. Rosenblatt MD, MPH

Department of Family Medicine, University of Washington School of Medicine, Seattle, Wash
Conflicts of interest: none reported

\section{CORRESPONDING AUTHOR}

Roger A. Rosenblatt, MD, MPH Department of Family Medicine Box 354696

School of Medicine

University of Washington

Seattle, WA 98195

rosenb@u.washington.edu

\begin{abstract}
Modern medical care is a 2-edged sword. Technical advances have improved our ability to diagnosis and treat disease, but they can also create a frightening, painful and bewildering environment for the patient seeking care. In this essay, the author shares his recent encounter with a life-threatening disease, emphasizing the unique contributions of the family physician to patient care, and pointing out some of the pitfalls of new communication tools such as e-mail.
\end{abstract}

Ann Fam Med 2004;2:175-176. DOI: 10.1370/afm.93.

" ome take a look at this," the pathologist said. He and the urologist were peering through the separate eyepieces of a teaching microscope. I looked at the specimen, stained a delicate pink and blue, and followed as he showed me the nests of cancer cells infiltrating the normal architecture of the surrounding prostate gland. As I looked at the spread of these malignant interlopers, I felt dizzy.

"You guys go on without me," I said. "I'll meet you back in the room." The "room" was a gloomy examining room in the nearby urology clinic, adorned with pictures of diseased prostates. So I went and sat, still a bit unsteady, on the examining table. The prostate tissue was mine, the brightly colored product of a biopsy done 2 weeks earlier.

My colleagues at University Hospital assumed that I would want to join them in reviewing the biopsy. The biopsy was critical in selecting the best treatment option, the virulence, extent, and distribution of the cancer would determine whether I had a chance of being cured. But their fascinating intellectual exercise was my potential death sentence. Perhaps they thought that I would be comforted by assuming the mantle of physician as I looked at these crisp slices of myself under the lens. Being a physician did not inoculate me from the terror of confronting the reality that I had cancer.

I had gotten the first inkling of the biopsy results the week earlier in the disembodied text of an e-mail, sent by the urologist's assistant. The email read: "Have you looked at the path report yet? Call the urology clinic and make an immediate appointment." While not exactly informative, it was clear that the news wasn't good. The biopsy had been excruciating, but this was worse. After being skewered like a shish kebab, the e-mail was like a second biopsy needle, but this time through the heart. Furthermore, I was expected to review the pathology results by myself, using our university's electronic medical record.

Looking at the pathology report on the computer was a devastating experience. The first reading of the biopsy did not look promising: the cells were quite malignant, and there were lots of them spread liberally throughout my hapless prostate gland. By pure chance my family physician had come to the university for a medical conference, and I waited until he stopped by my office to actually look at the report. Having a caring human being with me helped me deal with the shock, though it still seemed like a terrible way to convey the information. 
The subsequent staging of my cancer was a cascade of successive tortures. Blood draws rarely succeeded on the first try, and by the time I made it to surgery, most of my veins had collapsed in protest. The interminable CAT scan occurred in the evening, long after the radiologists had gone home, meaning that I got to sweat out the results through the ensuing sleepless night. Colleagues whom I had not told of my disease came up and commiserated: I appreciated their concern, but it was clear that medical privacy was unlikely in an institution where I had worked for 30 years. In fact, as I went through the diagnostic mill, treating physicians would tell me stories about the cancers of others on the staff, thinking it would make me feel better to know that I wasn't alone. Although it had that effect, I also realized that my case would be grist for future discussions among my colleagues.

By the time I made it to the surgical suite, I was a wreck. The surgery went well — the surgeon was talented, quick, and detached-and the final prognosis was better than the biopsy had suggested. The experience, however, was very traumatic, and not only because of the life-threatening nature of the underlying illness.

Does it have to be this way? Perhaps it does. The very things that make tertiary centers what they are-high patient volumes, complex technology, and efficiency - also make it difficult to forge nurturing relationships between healers and patients. Skilled specialists taking care of critically ill patients need to distance themselves to maintain their own emotional equilibrium. I made the task more difficult for my physicians because I was so much like them, and I understand why they treated me more like a physician than a patient. Family physicians can mitigate, but not annul, the terrors of serious disease, and they live in the same shadow of mortality that falls on everyone.

The lessons I learned from this journey reverberate through my personal and professional life. My medical students and patients helped me regain my footing, and I realize what a precious gift it is to be able to help other people realize their own dreams. I spend more time with my family and no longer form judgments or give advice. And I listen - to the wind, the birds, and to my fellow creatures who wrestle with the mystery, majesty, and pain of their own brief sojourn on earth.

To read commentaries or to post a response to this article, see it online at http://www.annfammed.org/cgi/content/full/2/2/175.

Key words: Education/training; health care delivery; health services research; patient care; prostate cancer

Submitted May 20, 2003; submitted, revised, July 31, 2003; accepted August 20, 2003. 